\title{
Analysis of the DNA-binding and activation properties of the human transcription factor AP-2
}

\author{
Trevor Williams ${ }^{1}$ and Robert Tjian \\ Howard Hughes Medical Institute, Department of Molecular and Cell Biology, University of California at Berkeley, \\ Berkeley, California 94720 USA
}

\begin{abstract}
The mammalian transcription factor AP-2 is a sequence-specific DNA-binding protein expressed in neural crest lineages and regulated by retinoic acid. Here we report a structure/function analysis of the DNA-binding and transcription activation properties of the AP-2 protein. DNA contact studies indicate that AP-2 binds as a dimer to a palindromic recognition sequence. Furthermore, cross-linking and immunoprecipitation data illustrate that AP-2 exists as a dimer even in the absence of DNA. Examination of cDNA mutants reveals that the sequences responsible for DNA binding are located in the carboxy-terminal half of the protein. In addition, a domain mediating dimerization forms an integral component of this DNA-binding structure. Expression of AP-2 in mammalian cells demonstrates that transcriptional activation requires an additional amino-terminal domain that contains an unusually high concentration of proline residues. This proline-rich activation domain also functions when attached to the heterologous DNA-binding region of the GAL4 protein. This study reveals that although AP-2 shares an underlying modular organization with other transcription factors, the regions of AP-2 involved in transcriptional activation and DNA binding/dimerization have novel sequence characteristics.
\end{abstract}

[Key Words: Enhancer factor; DNA binding; dimerization; mammalian expression; proline-rich activator; palindromic binding site]

Received November 15, 1990; revised version accepted January 22, 1991.

Sequence-specific DNA-binding proteins form a vital link between cis-regulatory DNA elements, present in promoter and enhancer sequences, and the general transcription machinery. Modulation of the concentration and activity of these proteins provides a fundamental mechanism for regulating gene expression. Alterations in the pattern of expression of DNA-binding transcription factors can lead to new programs of gene transcription during development. The modification of the activity of a pre-existing transcription factor represents one of the fastest methods for a cell to alter its pattern of gene expression in response to extracellular stimuli. Furthermore, aberrant transcription factor expression can be associated with oncogenesis. The delineation of the domains responsible for DNA-binding and transcriptional activation provides important clues toward understanding how these factors influence gene expression (Ptashne 1988; Mitchell and Tjian 1989).

The mammalian enhancer-binding protein AP-2 presents an attractive system to study the regulation of transcription factor activity. This protein is controlled at the level of its own gene expression (Williams et al. 1988; Lüscher et al. 1989| and may also be regulated

${ }^{1}$ Corresponding author. post-translationally (Mitchell et al. 1987). The AP-2 protein binds to a GC-rich recognition sequence present in the cis-regulatory regions of several viral and cellular genes, including the enhancers of SV40, HTLV-1, human metallothionein IIa, and mouse major histocompatibility complex (MHC) H-2K $\mathrm{K}^{\mathrm{b}}$ (Imagawa et al. 1987; Mitchell et al. 1987; Nyborg and Dynan 1990). In addition, AP-2 can stimulate transcription in a binding site-dependent manner both in vivo and in vitro (Mitchell et al. 1987; Williams et al. 1988). Interestingly, the expression of AP2 mRNA and protein is stimulated by retinoic acid-induced differentiation of human NT2 teratocarcinoma cells (Williams et al. 1988; Lüscher et al. 1989). Furthermore, AP-2 is expressed in a cell-type-specific manner; AP-2 is absent in the human hepatoma cell line HepG2 but present in human HeLa fibroblast cells (Williams et al. 1988). More recent data also show that AP-2 mRNA levels are regulated both temporally and spatially during mouse embryogenesis (Mitchell et al. 1991). Intriguingly, the highest levels of expression appear to correspond to early neural crest cells and suggest that AP-2 plays a role in their subsequent differentiation and development.

The activity of the AP-2 protein also appears to be controlled post-translationally by both positive and neg- 
ative regulatory mechanisms. Several studies suggest that AP-2 is displaced from its recognition site by competition from adjacent DNA-binding proteins (Israël et al. 1989, Mercurio and Karin 1989; Courtois et al. 1990). The DNA-binding activity of AP-2 can also be blocked by the SV40 large $T$ antigen oncogene product (Mitchell et al. 1987). In contrast, the ability of AP-2 to activate gene expression is stimulated by the hepatitis B virus $\mathrm{X}$ protein (Seto et al. 1990). The AP-2 DNA recognition sequence also seems to act as both a TPA- and cAMPinducible element (Imagawa et al. 1987; Roesler et al. 1988).

The examination of AP-2 activity has been facilitated by the recent cloning of a human cDNA encoding the entire AP-2 open reading frame (Williams et al. 1988). Expression of the full-length clone in Escherichia coli generated a protein that was indistinguishable from the endogenous HeLa factor in its ability to bind DNA and activate transcription. Here, we report the analysis of the DNA-binding and transcriptional activation properties of the AP-2 protein using a series of cDNA mutants. This analysis reveals that $\mathrm{AP}-2$ has a modular organization with separate domains involved in transcriptional activation and DNA binding/dimerization. The information obtained should enable us to dissect the mechanism of AP-2 action and understand how it may be regulated.

\section{Results}

\section{The AP-2 recognition sequence contains a dyad repeat}

The AP-2 protein must perform a minimum of two functions to act as a sequence-specific DNA-binding transcription factor. First, AP-2 must be able to recognize and bind to a specific DNA sequence; second, the protein must recruit the general transcription machinery to increase the rate of initiation. To analyze the former process we have examined which components of the AP-2 recognition sequence are important for specific protein/ DNA contact. Previously, DNase I footprinting experiments have shown that AP-2 binds to a GC-rich sequence that is present in a variety of promoter and enhancer elements associated with both viral and cellular genes (Imagawa et al. 1987; Mitchell et al. 1987). However, DNase I footprinting does not generate information concerning the contribution of individual nucleotides within the DNA-binding site. Therefore, to obtain a more detailed understanding of AP-2 DNA binding, we performed a series of methylation interference assays using the AP-2 sites present in the SV40 enhancer and the human metallothionein IIa distal basal level element (hMtIIa BLE). Methylation interference assesses the steric inhibition of DNA binding caused by the presence of an additional methyl group on guanine and adenine residues. In this procedure a DNA template was partially methylated and used for electrophoretic mobility-shift assays (EMSA) with AP-2 protein. Subsequently, the bound and free probes were isolated, cleaved with piperidine, and analyzed on a denaturing polyacrylamide gel. The results of the methylation interference experiments are summarized in Figure 1A. These studies reveal the occurrence of a consensus sequence, $5^{\prime}-\mathrm{GN}_{4} \mathrm{GGG}^{-} 3^{\prime}$, present on one strand of both the SV40 and hMtIIa-binding sites. Furthermore, a slightly degenerate copy of this sequence also occurs on the two complementary strands. Thus, the AP-2-binding site appears to contain a dyad repeat. Methylation of the guanine present at the center of the dyad repeat does not affect AP-2 DNA binding. In contrast, methylation of the flanking guanines present in the 5'-GN ${ }_{4}$ GGG-3' sequence reduces AP-2 binding to these sites.

To determine the contribution of all the individual bases within and around the binding sites we also performed missing contact probing assays. This procedure is used to determine how the removal of a particular base from the recognition site affects DNA binding. The experimental protocol was similar to methylation interference except that the starting DNA template was partially depurinated or depyrimidinated. Representative results obtained from this analysis are shown in Figure 1B, and the data are summarized schematically in Figure 1C. The data indicate that many bases within both the SV40 and hMtIIa sequences are needed to generate a functional AP-2 binding site. In addition, missing contact probing of the SV40 AP-2-site illustrates that flanking DNA sequences may also be important in the generation of a functional binding site. Interestingly, however, the removal of symmetrically located cytosine bases within the binding site does not affect AP-2 DNA binding (SV40 base pairs 233 and 237; hMtIIa base pairs - 177 and -173). Similarly, the cytosine present at the center of dyad symmetry is not important for protein/DNA contact. Molecular modeling indicates that these three cytosine bases can all be aligned on one face of the DNA helix and suggests that AP-2 is not contacting this region of the DNA (Fig. 1D). It is also interesting to note that the missing contact probing and methylation interference procedures measure different aspects of DNA binding, as AP- 2 can bind to the recognition sequence when the guanine at the center of dyad symmetry is methylated but not when it is removed. Taken together, the results show that the SV40 and hMtIIa sites share several common sequence features. Moreover, the data allow the identification of a palindromic sequence, 5'-GCCN ${ }_{3}$ GGC-3', which appears to form the core recognition element for the AP-2-binding site.

\section{The carboxy-terminal region of the AP-2 protein} mediates DNA binding

The determination of which nucleotides in the recognition site are involved in AP-2 DNA binding represents one aspect in the analysis of protein-DNA interaction. We then characterized which regions of the AP-2 peptide sequence were responsible for DNA binding. In this analysis mutant AP-2 polypeptides were synthesized by in vitro translation and assayed for their ability to bind an AP-2 site using EMSA. The results obtained, by using a series of amino- and carboxy-terminal deletion mutants, are illustrated in Figure 2A. Removal of the most amino- 


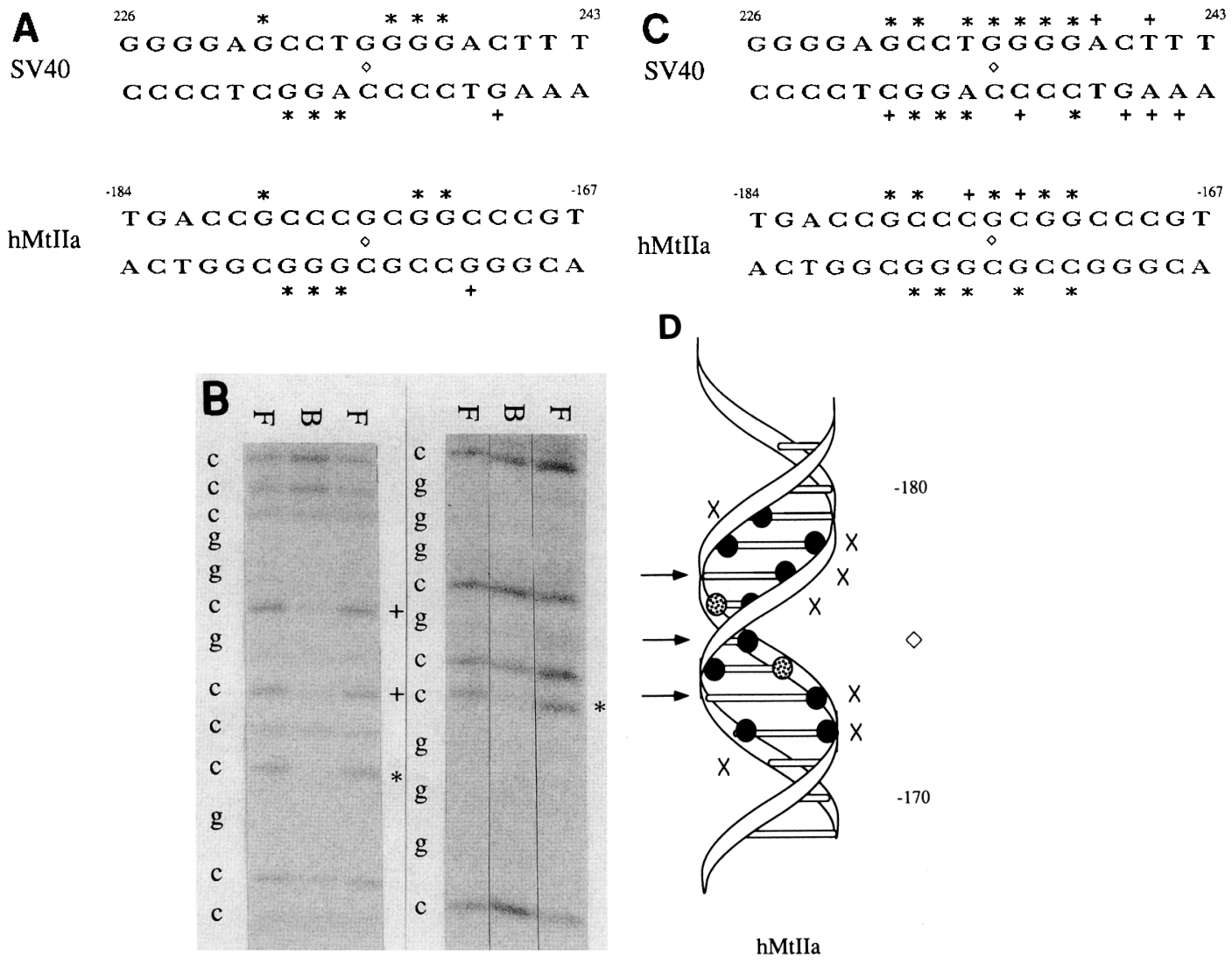

Figure 1. Analysis of the AP-2 DNA-binding site. (A) Summary of the methylation interference data obtained with the AP-2-binding sites present in the SV40 enhancer and the hMtIIa distal BLE. The asterisk (*) denotes $70-100 \%$ interference when this nucleotide is methylated; the plus sign $(+\mid$ indicates $30-70 \%$ interference, as determined by densitometry of autoradiograms. $|\Delta|$ The center of dyad symmetry. $(B)$ Pyrimidine $(C T)$ missing contact probing analysis performed on the top (left) and bottom (right) strands of the hMtIla AP-2 site. The sequence is presented beside the autoradiograms. The symbols * and + are as indicated in $A$, but here refer to interference caused by removal of that base. (Lanes $F$ and $B$ ) Sequencing ladders from free probe and AP-2 bound probe, respectively. $(C)$ Summary of the missing contact probing data obtained with the AP-2-binding sites present in the SV40 and hMtIIa enhancers. Symbols are as indicated in $B .(D)$ The methylation interference and missing contact probing data for the hMtIIa AP-2 site are superimposed on a DNA helix with 10.5 bp per helical turn. $(x)$ The bases contributing to methylation interference. (Solid circles) Bases that cause $70-100 \%$ interference when removed; (stippled circles) $30-70 \%$ interference. $(\rightarrow$ ) The three cytosines in the binding site that are not critical; $(\diamond)$ the center of dyad symmetry.

terminal 165 amino acids of AP-2 does not affect sequence-specific DNA binding to an oligonucleotide containing an AP-2 site (mutants $\Delta \mathrm{N} 30$ to $\Delta \mathrm{N} 165$ ). However, further deletion of the adjacent amino-terminal 62 amino acids completely abolishes DNA binding $(\Delta \mathrm{N} 227)$. The carboxy-terminal boundary of this DNAbinding domain is located within 50 amino acids of the carboxyl terminus of the protein $(\Delta \mathrm{C} 390)$. Analysis of the expression levels of the various deletion mutants indicates that they were all produced in comparable amounts (data not shown). Furthermore, these results were confirmed by DNase I footprinting, using bacterially expressed protein (data not shown). This analysis of the DNA-binding domain was refined by using further amino- and carboxy-terminal deletion mutants, and the data obtained are summarized in Figure 2B. The carboxyterminal boundary of the AP-2 DNA-binding domain is well defined. Removal of the last 28 amino acids of the protein has no effect on DNA binding ( $\triangle \mathrm{C} 409)$, whereas deletion of the next 19 residues abolishes this potential $(\Delta C 390)$. Similarly, the mutants $\Delta N 203$ and $\Delta N 227$, which are capable and incapable of binding DNA, respectively, place the amino-terminal boundary of the DNAbinding region between amino acids 204 and 227 . Therefore, the region of AP-2 that confers sequence-specific DNA binding resides in a stretch of $\sim 200$ amino acids located toward the carboxyl terminus of the protein. Analysis of the sequence reveals that the first half of this region contains an abundance of basic residues, whereas the latter half is potentially $\alpha$-helical in nature.

\section{The DNA-binding region contains a dimerization domain}

The finding that AP-2 binds to a palindromic recognition sequence implies that AP-2 may interact with DNA as a 


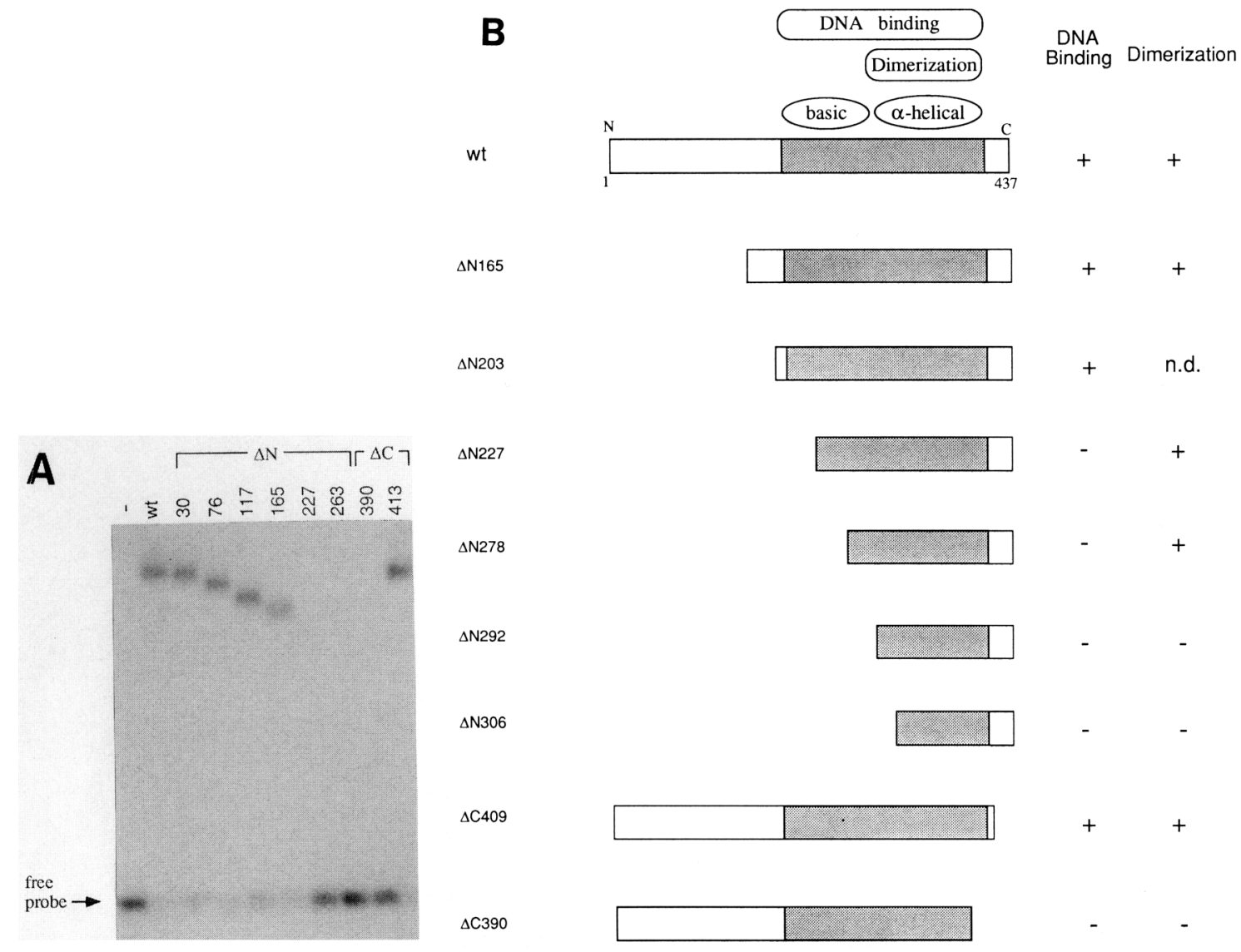

Figure 2. The AP-2 DNA-binding domain occupies the carboxy-terminal half of the protein. (A) EMSA performed using various AP-2 deletion mutants, as indicated above the lanes. Proteins were translated in vitro and incubated with a labeled hMtIIa AP-2 oligonucleotide. The position of the free probe is shown. $(-)$ No RNA was added to the in vitro translation system; (wt) full-length wild-type AP-2; $(\Delta \mathrm{N}$ and $\Delta \mathrm{C})$ the stated number of amino acid residues have been removed from the amino terminus or carboxyl terminus of the protein, respectively. $(B)$ Summary of the DNA-binding and dimerization abilities of AP-2 deletion mutants. The 437-amino-acid AP-2 open reading frame is represented by a box, with the shaded area indicating the sequences important for DNA-binding. The maximum extent of the DNA-binding and dimerization domains and the basic and $\alpha$-helical regions are shown by the ovals at the top. The ability of the protein to bind DNA in a sequence-specific manner, as determined by EMSA and DNase I footprinting, is summarized by + or - symbols, which refer to wild-type or undetectable binding, respectively. Dimerization refers to the potential of amino-terminal deletions to associate with the wild-type protein or the carboxy-terminal deletions to dimerize with $\Delta$ N165. (n.d.) Not done.

multimer. Moreover, the region of AP-2 required for DNA binding is quite large and suggests that, in addition to direct DNA contact, some auxiliary function may help stabilize the protein-DNA interaction, such as protein-protein contact between AP-2 molecules. Therefore, we have examined the ability of AP-2 to multimerize using EMSA (Fig. 3A). The in vitro-translated wildtype AP-2 protein produces a protein-DNA complex of slow mobility, whereas the $\Delta \mathrm{N} 165$ deletion mutant yields a faster migrating species. When these two proteins are cotranslated an intermediate band is produced, indicating the presence of a heteromeric complex. The absence of any intermediate band when the wild-type and $\Delta$ N165 mutant are mixed after separate translation demonstrates that there are not simply two independent binding sites on this DNA template. In addition it also shows that the multimer is relatively stable, as there is no obvious exchange between the wild-type and mutant complexes during the binding reaction. Further experiments indicate that the half-life of the heteromer exceeds $5 \mathrm{hr}$ (data not shown).

The EMSA experiment demonstrates that AP-2 binds to DNA as a stable multimer, but it does not directly address the nature of AP-2 in solution. For this purpose we performed glutaraldehyde cross-linking experiments in the absence of DNA. The wild-type protein was translated in vitro in the presence of $\left[{ }^{35}\right.$ S $]$ methionine and partially purified by sequence-specific DNA affinity chromatography. Following cross-linking, the proteins were resolved by SDS-PAGE and visualized by autoradiography. Figure 3B shows that the $50-\mathrm{kD}$ wild-type protein yields products of $\sim 100 \mathrm{kD}$ in the presence of glutaraldehyde, indicating that the protein exists as a dimer in solution. Similarly, the $30-\mathrm{kD} \Delta \mathrm{N} 165$ polypeptide generates a $60-\mathrm{kD}$ dimeric species upon cross-linking. In an analogous experiment to the EMSA shown in Figure 3A, 


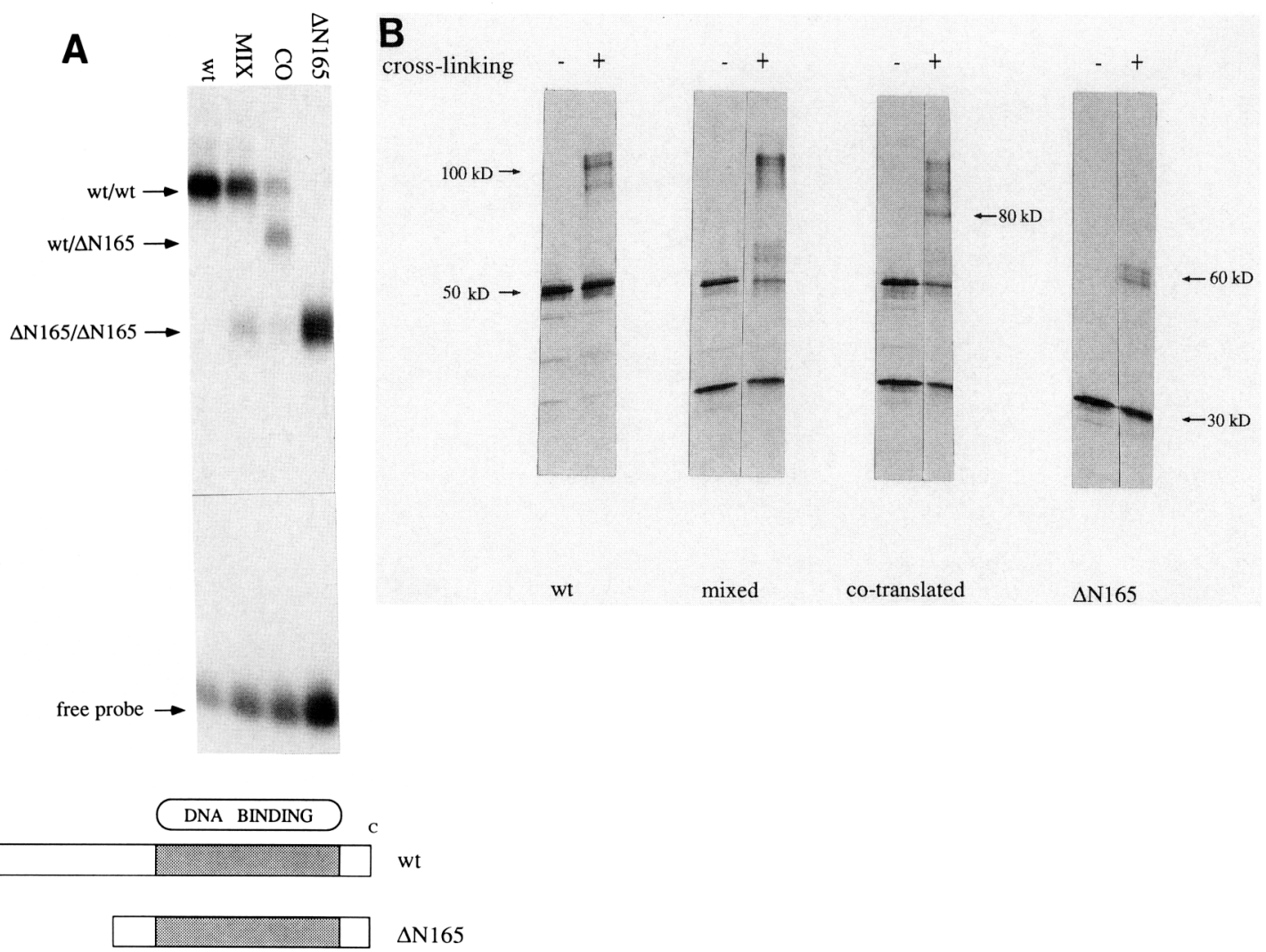

Figure 3. AP-2 is a dimer both when bound to DNA and in solution. $(A)$ EMSA performed using the wild-type (wt) and $\Delta$ N165 deletion mutant. The proteins were translated in vitro and incubated with a labeled hMtIIa AP-2 oligonucleotide. The DNA-binding reactions contained wild-type protein alone $(w t) ; \Delta \mathrm{N} 165$ protein alone $(\Delta \mathrm{N} 165) ;$ a mixture of the two proteins following separate translation $(\mathrm{MIX})$; or the two proteins cotranslated (CO). (B) Cross-linking performed with the wild-type (wt) and $\Delta N 165$ proteins. The proteins were translated in the presence of ${ }^{35} \mathrm{~S} \mid$ methionine and purified by DNA affinity chromatography. Aliquots of the proteins were either cross-linked with glutaraldehyde $(+)$ or left untreated $(-)$. The reaction products were resolved by SDS-PAGE and detected by fluorography.

the two proteins were also either cotranslated or mixed after separate translation. When the proteins are mixed and cross-linked only the $60-\mathrm{kD}$ mutant dimer and the $100-\mathrm{kD}$ wild-type dimer are generated. In contrast, an additional $80-\mathrm{kD}$ dimeric complex is also formed by the wild-type and $\Delta$ N165 proteins when they are cotranslated. This indicates that the appearance of dimers is not simply a random cross-linking event but a specific protein-protein interaction that occurs in the absence of DNA. Furthermore, because the $\Delta \mathrm{N} 165$ mutant represents approximately the minimum polypeptide required for DNA contact, the EMSA and cross-linking data indicate that the domain responsible for dimerization is part of the DNA-binding region.

To further localize the dimerization domain we have utilized a coimmunoprecipitation assay. This method enables complex formation to be studied in mutants that are incapable of binding to DNA. Antiserum directed against an amino-terminal polypeptide will recognize the wild-type protein but not amino-terminal deletion mutants (Fig. 4A). However, if these mutants can dimerize with the wild-type protein they will be purified by coimmunoprecipitation. Figure $4 \mathrm{~A}$ illustrates that the
$\Delta$ N165 mutant is only immunoprecipitated when it is cotranslated with the wild-type protein, again indicating that it is capable of forming a stable dimer in the absence of DNA. Moreover, the $\triangle N 278$ polypeptide can also stably associate with the wild type (Fig. 4A), even though it is unable to bind to DNA. However, deletion of the amino-terminal 306 amino acids of the protein abolishes the ability of the polypeptide to associate with the wild type, indicating that a domain important for complex formation has been destroyed. A similar set of experiments were performed with a series of carboxy-terminal deletion mutants. However, because the wild-type and carboxy-terminal deletions of interest were of similar size, it was simpler to determine whether the mutant proteins could associate with the shorter $\Delta$ N165. Figure 4B shows the results obtained when an antiserum raised against an amino-terminal peptide was used to precipitate the carboxy-terminal deletions and any associated $\Delta 165$. In common with the wild type, the $\Delta C 409$ mutant is capable of dimerizing with the $\Delta \mathrm{N} 165$ protein when they are cotranslated but not mixed. In contrast, the $\Delta$ C390 mutant has lost the ability to complex with the $\Delta$ N165 protein. These data were also confirmed by glu- 


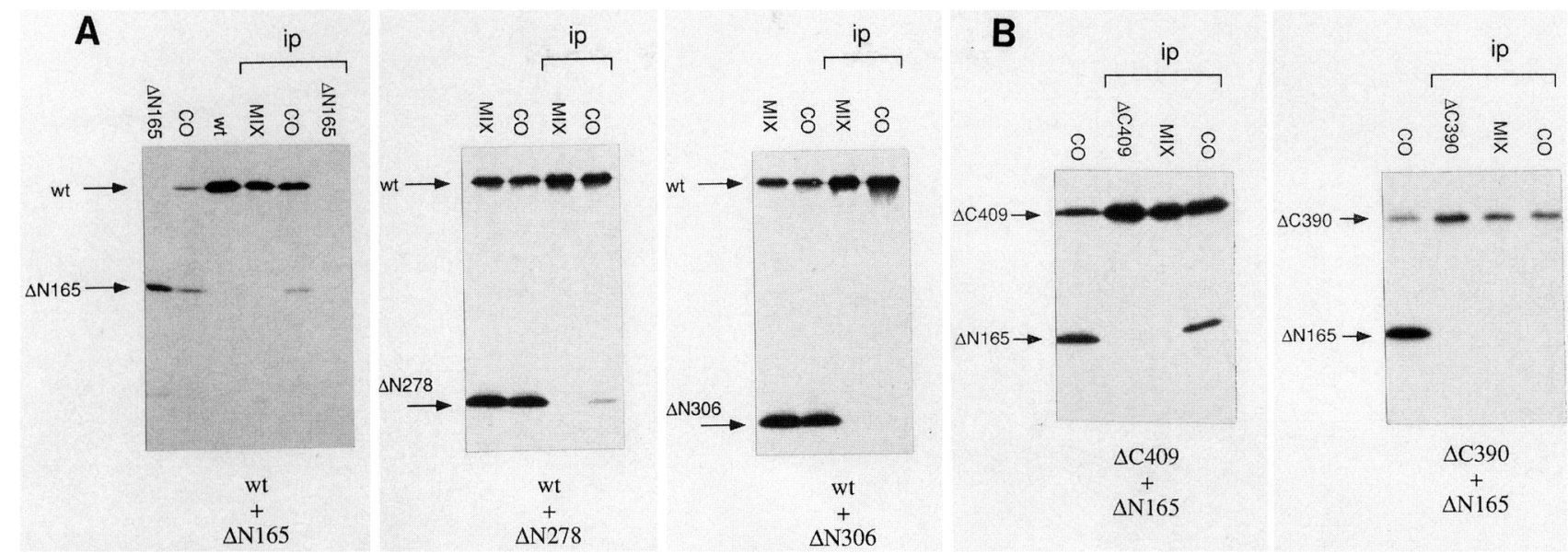

Figure 4. The dimerization domain of AP-2 is an integral part of the DNA-binding domain. $(A)$ Coimmunoprecipitation of aminoterminal deletion mutants with wild-type AP-2. Proteins were expressed in vitro in the presence of $\left[{ }^{35} S\right]$ methionine, immunoprecipitated with an antisera specific for amino-terminal peptide sequence of full-length AP-2, separated by SDS-PAGE, and visualized by autoradiography. The mutants analyzed for their ability to coimmunoprecipitate with AP-2 are shown beneath each panel. (MIX) The two proteins were mixed after separate translation; $(\mathrm{CO})$ the proteins were cotranslated. Lanes not covered by brackets are protein samples before immunoprecipitation. Lanes bracketed with ip are the samples obtained following immunoprecipitation. $(B)$ Coimmunoprecipitation of $\triangle \mathrm{Nl} 65$ with various carboxy-terminal deletion mutants. Labels and methods are as in $A$. Note that the proteins are labeled with $\left[{ }^{35} S\right]$ methionine and that $\Delta N 165, \Delta C 409$, and $\Delta C 390$ have 4,3 , and 2 methionines, respectively.

taraldehyde cross-linking studies (data not shown), and the results from these and other mutants are summarized schematically in Figure 2B.

All of the proteins that can interact with DNA occur as stable dimers in solution. In addition, all of the proteins that do not dimerize have lost the ability to bind DNA. This strongly suggests that dimerization is a prerequisite for AP-2 DNA binding. Interestingly, two mutants that have lost the ability to bind DNA are still capable of dimerizing $(\Delta \mathrm{N} 227$ and $\Delta \mathrm{N} 278)$. Therefore, the sequences responsible for dimerization are situated between amino acids 278 and 409 . These results indicate that the dimerization domain forms an integral part of the DNA-binding region.

\section{A short proline-rich sequence mediates AP-2 transcriptional activation}

The $50-\mathrm{kD}$ AP-2 protein possesses a minimum of two functions, namely DNA binding and transcriptional activation. It was possible that these two properties exist in separate domains of the molecule (Ptashne 1988; Mitchell and Tiian 1989) or, alternatively, that they were intimately linked together (Hochschild et al. 1983; Hollenberg et al. 1987; Miesfeld et al. 1987). To ascertain which AP-2 sequences were responsible for transcriptional activation we performed cotransfection experiments. Previously, Drosophila Schneider cells were used as an in vivo complementation system to assay for AP-2 transcriptional activation (Williams et al. 1988). However, it would also be useful to assess the ability of AP-2 to stimulate gene expression in mammalian systems. We chose to test the transcriptional properties of cotransfected AP-2 in the human hepatoma cell line HepG2, which lacks endogenous AP-2 mRNA and protein
(Williams et al. 1988). The AP-2-coding region was introduced into these cells under the control of the Rous sarcoma virus long terminal repeat (RSV LTR) in the expression vector SPRSV-AP2 (Fig. 5C). The reporter construct used in these experiments, termed A2BCAT (Fig. 5B), contains a triplicated AP-2-binding site placed upstream of the adenovirus E1G TATA box. Figure 5A shows that the A2BCAT reporter plasmid has a very low basal level of CAT activity that is greatly stimulated by the addition of cotransfected AP-2. In contrast, AP-2 has no effect on the BCAT plasmid lacking the AP-2-binding sites. This result demonstrates that AP-2 is capable of activating gene expression in a binding site-dependent manner in vivo in mammalian cells.

The availability of these expression and reporter plasmids now enabled the regions of AP-2 responsible for transcriptional activation to be localized. A series of $5^{\prime}$, $3^{\prime}$, and internal deletion mutants were inserted into the SPRSV expression vector and tested in the HepG2 cell cotransfection assay. Figure 6 provides a schematic summary of the results obtained with these mutants. The amino-terminal deletions indicate that removal of 14 amino acids between residues 51 and 65 severely reduces trans-activation by AP-2 $(\Delta \mathrm{N} 51$ and $\Delta \mathrm{N} 65)$. Furthermore, the ability of the protein to stimulate gene expression is abolished by deletion of the next 12 amino acids $(\Delta N 77)$. More extensive deletions toward the carboxyl terminus are also inactive (data not shown). In addition, the major importance of amino acids $31-77$ is confirmed by the internal deletion INT $31 / 77$, which makes the protein inactive in this assay. Interestingly, examination of this region of the protein reveals a sequence unusually rich in proline residues ( $30 \%$; see Fig. $8 \mathrm{C}$, below).

The internal deletions also indicate that other regions of the protein may contribute to trans-activation by AP- 
A

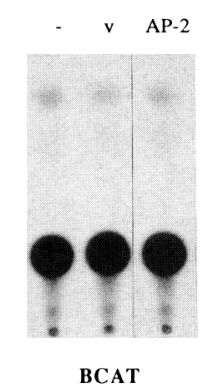

BCAT

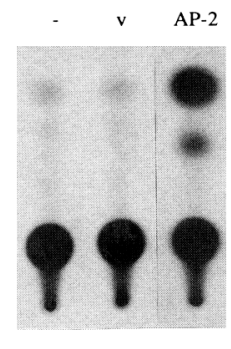

A2BCAT
B

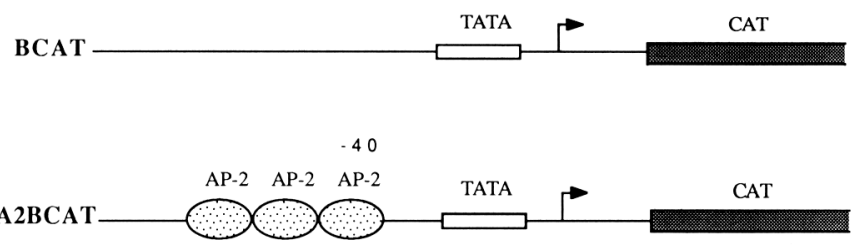

C

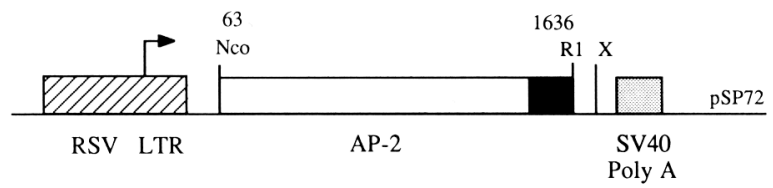

Figure 5. AP-2 expressed in vivo in mammalian cells activates transcription in a binding site-dependent manner. $(A) \mathrm{CAT}$ assay demonstrating AP-2 activation of gene expression in HepG2 cells. The reporter constructs are indicated below each panel. The cells were transfected with reporter plasmid alone $(-)$; reporter plasmid and the expression vector with no insert, SPRSV (v); reporter plasmid and the expression vector containing AP-2, SPRSV-AP2 (AP-2). (B) Schematic diagrams of the CAT reporter templates used in the cotransfection assays. A2BCAT contains the adenovirus Elb TATA box with three copies of a 19-bp hMtIIa AP-2-binding site. BCAT contains only the E1b TATA box. The start sites and direction of transcription are shown by arrows; the AP-2-binding sites are shown by dotted ovals. $(C)$ Schematic representation of the AP- 2 mammalian expression vector SPRSV-AP2. The RSV LTR (hatched box), the start site of transcription (arrow), and the SV40 poly(A) addition sequence (stippled box) are indicated. The AP-2 open reading frame (open box), from the ATG at nucleotide 63 to the TGA at nucleotide 1376, and $3^{\prime}$-untranslated region (solid box) are also shown. The NcoI site (Nco) at the $5^{\prime}$ end of the open reading frame, the EcoRI (R1) site at the $3^{\prime}$ end of the AP- 2 sequences, and the XhoI site (X) used for cloning are indicated. All nucleotide numbers are given with respect to the sequence of AP2-9 (Williams et al. 1988).

2. In particular, a deletion of 48 amino acids, which removes a region of net acidic charge, reduces stimulation of gene expression fourfold (INT 123/171). As expected, carboxy-terminal deletions that impinge on the DNAbinding domain fail to activate transcription $(\Delta \mathrm{C} 390)$.

Taken together, these data indicate that transcriptional activation by AP- 2 relies on at least two distinct parts of the protein, the carboxy-terminal DNA-binding domain and an amino-terminal proline-rich sequence. However, the relative activity of the protein is also disrupted by a series of internal deletions. This suggests that several regions of the protein may need to interact correctly to generate a functional AP-2 molecule. Indeed, the in vivo cotransfection assay actually measures the sum of a number of parameters, including protein stability, nuclear localization, and ability to activate transcription. To examine some of these possibilities we have determined whether the proteins are correctly expressed and localized in vivo. Nuclear and cytoplasmic extracts were prepared from transfected HepG2 cells, and the presence of AP-2 derivatives was determined by immunoblotting (data not shown). The data indicated that the wild-type and mutant constructs containing an intact DNA-binding domain were all expressed and translocated to the nucleus.

The AP-2 proline-rich region activates gene expression when linked to the GAL4 DNA-binding domain

An alternative method in determining whether a particular region of AP-2 is capable of activating gene expres- sion is to link it to a heterologous DNA-binding domain. The well-characterized yeast GAL4 DNA-binding protein provides a useful recipient for this type of assay because there is no endogenous GAL4-like activity in mammalian cells (Ptashne 1988). Therefore, the 147amino-acid GAL4 DNA-binding domain was attached amino-terminal to several AP- 2 polypeptides, and the activating potential of the chimeric constructs was tested by cotransfecting them with a GAL4 reporter construct. Figure 7 summarizes the data obtained when various GAL4/AP-2 fusions were cotransfected into HepG2 cells with the G5BCAT reporter construct, which contains five GAL4-binding sites upstream of the adenovirus E1B TATA box (Lillie and Green 1989).

The GAL4 DNA-binding domain alone was unable to activate CAT expression in this assay (Fig. 7; Ptashne 1988). However, when the proline-rich region of AP-2 was attached to GAL4 (GAL4 +6/77), the resulting fusion could potently activate expression, consistent with the observation that this region was the most important single component in the context of AP-2 itself. Furthermore, the inclusion of the adjacent carboxy-terminal 40 amino acids leads to an approximately fourfold increase in transactivation (GAL4 +6/117). This sequence produces a similar effect on the activating properties of wild-type AP-2 (Fig. 5; INT 77/117) and also contains a high concentration of prolines (see Fig. 8C). Addition of the adjoining acidic region to the proline-rich sequence does not augment expression further (GAL4 +6/165), and this acidic region alone produces only a mild stimulation of gene expression (GAL4 +117/165). Intriguingly, the fusion of essentially wild-type AP-2 to the GAL4 
wt

$$
\Delta \mathrm{N} 51
$$

$\Delta \mathrm{N} 65$

$\Delta \mathrm{N} 77$

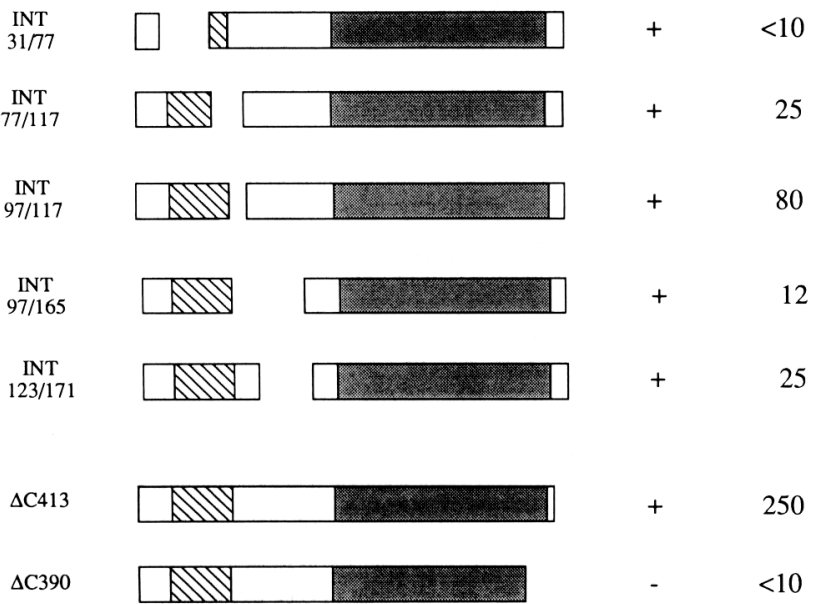

Figure 6. Summary of the transcription activation potential of AP-2 deletion mutants. The AP-2 protein is shown as a box, with the DNA-binding domain (shaded), proline-rich region (hatching; Pro), and region containing a high concentration of acidic residues labeled. For the internal deletion mutants (INT) the first and second number refer to the last amino acid present before the deletion and the first amino acid present after the deletion, respectively. $(+)$ Wild-type DNA binding. The induction of CAT activity, averaged over several experiments, is normalized to wild-type AP-2, which was assigned a value of 100 . The value $<10$ indicates that no detectable stimulation of the reporter construct was observed.

DNA-binding domain generates an inactive construct [GAL4 +6/437). A similar observation was also noted for a chimera between the CTF and Spl DNA-binding proteins (Mermod et al. 1989). It is therefore possible that fusion proteins possessing two distinct DNA-binding specificities may often be nonfunctional. In conclusion, these data demonstrate that a region of high proline content, located toward the amino terminus of AP-2, acts as a potent trans-activation domain. Moreover, this domain can function not only in association with the homologous AP-2 DNA-binding region but also with the heterologous GAL4 DNA-binding domain.

\section{Discussion}

In this report we have localized the sequences responsible for DNA binding, dimerization, and transcriptional activation (Fig. 8A). Furthermore, we have identified the components of the AP- 2 recognition sequence that are required for protein-DNA interaction. Analysis of the SV40 and human metallothionein IIa (hMtIIa) AP-2 DNA recognition sites by methylation interference and missing contact probing reveals the presence of a palindromic consensus sequence, $5^{\prime}$-GCCN ${ }_{3}$ GGC- $3^{\prime}$, present at the core of this element. This palindromic design for the consensus sequence is supported by methylation protection and interference data obtained from the AP-2 sites present within the mouse MHC $\mathrm{H}-2 \mathrm{~K}^{\mathrm{b}}$ and human growth hormone promoters, respectively (Israël et al. 1989; Courtois et al. 1990). The presence of a palindrome in the recognition sequence is consistent with the observation that AP-2 binds to DNA as a dimer (Fig. 3A). Our designation of an AP-2 consensus sequence is slightly different from those originally formulated (Imagawa et al. 1987; Mitchell et al. 1987) but agrees well with the EMSA competition data obtained by using mutations spanning the SV40 enhancer core (Macchi et al. 1989). However, it is worth noting that many AP-2-binding
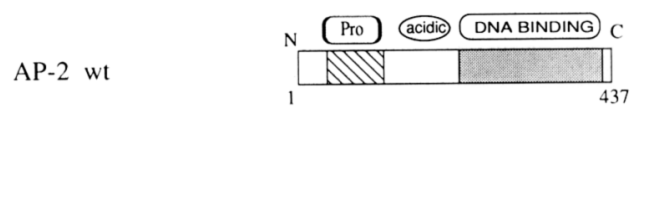

Gal4 147N

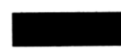

Fold Induction over basal CAT Activity

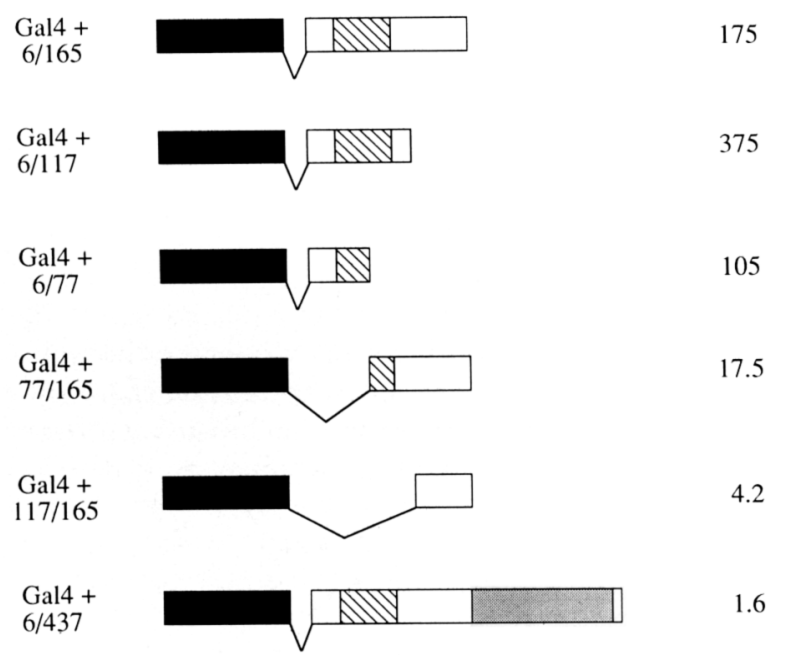

Figure 7. The proline-rich region of AP-2 activates transcription when attached to the GAL4 DNA-binding domain. Transfection experiments were performed as in Fig. 5 but using the Gal4 reporter construct G5BCAT. The structure of AP-2 is shown at the top, as in Fig. 6. The GAL4 DNA-binding domain is represented by a solid box, and the numbers refer to the AP-2 amino acids present in each construct. Values of CAT inductions were calculated as the ratio of activities obtained with the indicated expression plasmids, relative to the basal activity of the reporter construct alone. 
A

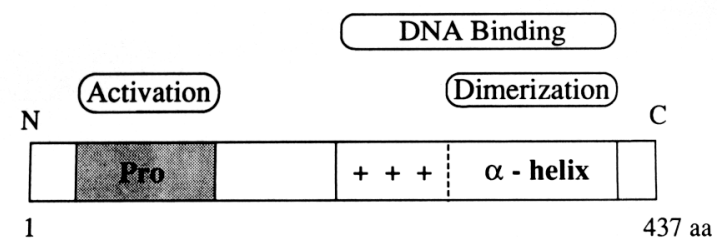

B

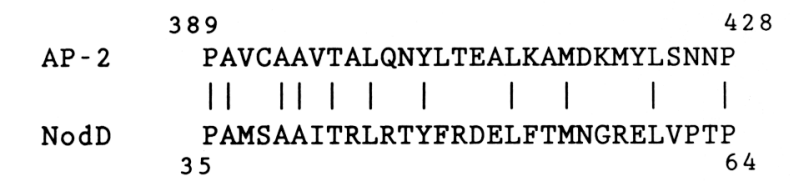

$\mathbf{C}$

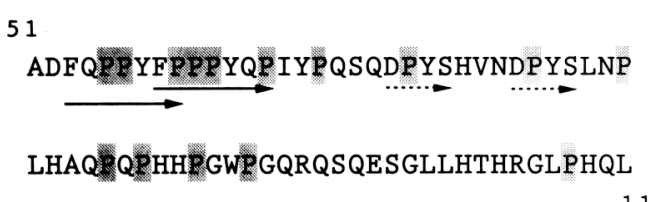

118

Figure 8. Regions of the AP-2 protein required for DNA binding, dimerization, and transcriptional activation. $(A)$ Modular structure of the AP-2 protein indicating the positively charged region and $\alpha$-helical dimerization domain, which together are responsible for DNA binding, and the proline-rich activation domain (shaded box; Pro). (B) Homology between part of the DNA-binding/dimerization domain of AP-2 and the bacterial DNA-binding protein, NodD (Appelbaum et al. 1988). Numbers refer to the amino acid sequence of the proteins. $(C)$ Sequence of the proline-rich (shaded $\mathrm{P}$ ) transcriptional activation domain of AP-2. Numbers refer to the amino acid sequence of the protein. Arrows indicate the two pairs of direct repeats.

sites deviate from this consensus. Interestingly, the missing contact probing studies also indicate that AP-2 relies on many bases to stabilize the protein-DNA interaction, and the majority of these nucleotides seem to occur on one side of the DNA helix. However, it is unlikely that AP-2 relies solely on contacts with bases to achieve DNA binding, and preliminary ethylation interference experiments suggest that AP-2 may also interact with the phosphate backbone (T. Williams, unpubl.). These studies will help in determining a more accurate structural model of the interactions of the AP-2 protein with its DNA recognition sequence.

Concomitant with the analysis of the nucleotide sequences involved in AP-2 DNA recognition, we have determined which regions of the AP- 2 protein constitute the DNA-binding domain. A region of $\sim 200$ amino acids, located toward the carboxyl terminus of AP-2, is sufficient to produce sequence-specific DNA binding. Our analysis also demonstrates that AP- 2 binds to DNA as a dimer, consistent with the dyad symmetry present in the AP-2-binding site. The AP-2 protein also occurs as a dimer in solution. Interestingly, all of the AP-2 deletion mutants that bind to DNA can dimerize, whereas the mutants that do not dimerize have also lost their DNAbinding potential. Therefore, dimer formation is apparently an essential requirement for AP-2 protein-DNA interaction, and the dimerization domain forms an integral component of the DNA-binding region. Examination of the amino acid sequence reveals that the aminoterminal half of the DNA-binding region has an abundance of basic residues. In contrast, the latter half of this region, which corresponds to the dimerization domain, is potentially $\alpha$-helical in nature. Therefore, one might predict that the basic region will directly contact the DNA, while the dimerization domain stabilizes this protein-DNA contact by a protein-protein interaction. Alternatively, the region involved in dimerization might also contain some residues participating directly in DNA binding. The AP-2 DNA-binding sequences do not resemble those from other transcription factors, such as the homeo box, zinc fingers, or HMG box (Evans and Hollenberg 1988; Herr et al. 1988; Hoey and Levine 1988; Jantzen et al. 1990). Interestingly, though, the overall organization of the AP-2 DNA-binding domain is reminiscent of the bZIP and HLH proteins, where a basic region in association with an adjacent dimerization domain mediates stable DNA contact (Landschulz et al. 1989; Murre et al. 1989; Jones 1990). However, the dimerization domain of AP-2 does not contain a leucine repeat, nor does it share any homology with the HLH motif. The sequences responsible for AP-2 dimerization are approximately twice the length of these other domains. A number of internal deletions in the AP-2 dimerization domain suggest that it possesses a novel design that we term a helix-span-helix (HSH) structure (Williams and Tjian 1991). The presence of a dimerization domain also raises the intriguing possibility that the activity of AP- 2 may be regulated by association with other proteins possessing this HSH motif. This type of mechanism provides an important method to control the activities of many bZIP and HLH proteins, including cjun and myoD (Benezra et al. 1990; Garrell and Modolell 1990; Jones 1990).

The number of sequence motifs that have been classified as DNA-binding domains continues to expand as more transcription factors are analyzed. Recently, novel DNA-binding sequences have been identified in several factors, including CTF/NF1 (Mermod et al. 1989) and SRF (Norman et al. 1988). The extended DNA-binding domain of AP-2, which occupies half of the protein, also appears to represent a new type of structure. However, it is possible that the tertiary structure of several of these proteins may be similar. In this context it is worth noting that AP-2 contains a stretch of amino acids with weak sequence similarity to a bacterial DNA-binding protein, NodD (Fig. 8B; Appelbaum et al. 1988).

A number of studies indicate that the AP-2 DNA-binding site is an important component of several upstream regulatory regions (Karin et al. 1987; Hyman et al. 1989). 
However, conflicting data exist concerning the relative importance of the AP-2 site when it is isolated from other cis-regulatory elements in minimal promoter constructs. The AP-2 protein is able to activate gene expression in an in vitro-reconstituted transcription system derived from HeLa cells (Mitchell et al. 1987). Furthermore, Imagawa et al. (1987) reported that the AP2-binding site could act as an inducible enhancer element in vivo in HeLa cells. In contrast, Kanno et al. (1989) observed that the AP-2 site did not produce any transcriptional stimulation in these cells. Potentially, this disparity could simply reflect the different context of the AP-2 DNA-binding sites in these reporter constructs.

Here, we have shown that the AP-2 DNA-binding site can function as a cis-regulatory element in vivo in mammalian HepG2 cells. Consistent with the observation that AP-2 is normally absent from these HepG2 cells (Williams et al. 1988), the presence of several AP2-binding sites does not alter the level of expression from a minimal promoter construct. The subsequent addition of exogenous AP-2 by transfection leads to a 5- to 10-fold binding site-dependent increase in expression. These experiments have also been extended to HeLa cells, which already possess endogenous AP-2 protein. Interestingly, we observed that the presence of AP-2 sites in our reporter construct did not increase the basal level expression obtained with the minimal BCAT plasmid. Moreover, the addition of the AP-2 expression plasmid into the HeLa cells caused a significant binding site-dependent increase of promoter activity (data not shown). Therefore, AP-2 can also function as a transcription factor in vivo in HeLa cells. However, it appears that the endogenous AP-2 in HeLa cells is unable to stimulate transcription from a transfected reporter plasmid containing AP-2 sites. One possible explanation for this observation is that the amount of AP-2 in these cells is below a threshold level for activation. Such a threshold could simply reflect low amounts of AP-2 in HeLa cells, where it might be unable to compete with other proteins for DNA and the general transcriptional machinery. Alternatively, it is possible that the activity of endogenous AP-2 is under negative control, a process that has been observed for several transcription factors including c-jun and NFאB (Baeuerle and Baltimore 1988; Baichwal and Tjian 1990). For both of these alternatives a rise in the level of AP-2 protein resulting from transfection could overcome this threshold. An increase in transcription from an AP-2 reporter construct is observed in NT2 teratocarcinoma cells following retinoic acid-induced differentiation, which raises the levels of AP-2 protein in these cells (Lüscher et al. 1989). Therefore, one would predict that AP-2 might function as a more potent transcriptional activator in cells of the neural crest lineage where it is expressed in high levels (Mitchell et al. 1991).

We have transfected mutant AP-2 cDNA constructs into HepG2 cells to delineate the sequences necessary for transcriptional activation. The major activation domain of AP- 2 occupies a region of $\sim 80$ amino acids near the amino terminus of the protein (Fig. 8). This region also stimulates gene expression when attached carboxyterminal to the DNA-binding domain of the GAL4 protein. The most distinguishing feature of the activation domain is the high content of proline residues, which constitute $30 \%$ of the amino acid sequence in the most important part of this region (Fig. $8 \mathrm{C}$ ). In this respect AP-2 resembles the transcription factors CTF/NF1 and OTF-2, which also contain proline-rich activation domains (Mermod et al. 1989; Gerster et al. 1990). Therefore, the proline residues present in these domains may provide the essential link to the RNA polymerase II transcriptional machinery. Alternatively, it is possible that the prolines could form a rigid structural framework that enables other critical residues to interact with the general factors. However, there is no obvious further similarity between the activating sequences of AP-2 and $\mathrm{CTF} / \mathrm{NF} 1$ proteins. Indeed, a notable feature of the AP-2 activation domain is that it contains several aromatic amino acids $(Y, F, W)$, which appear to be critical in some activation domains but do not occur in the activating region of certain forms of CTF/NF1 (Mermod et al. 1989; Cress and Triezenberg 1991), Interestingly, examination of the AP-2 activating sequence (Fig. $8 \mathrm{C}$ ) reveals one long overlapping repeat (FQPPYFP/FPPPYQP) and one short repeat (DPYS/DPYS), which might indicate some reiterated structural motif. Moreover, a sequence similar to the longer of these repeats is also present at the carboxyl terminus of the OTF-2 proline-rich transcriptional activation domain (PAPYQP) (Gerster et al. 1990).

A number of amino acid motifs have been defined as transcriptional activators, including acidic, glutaminerich, and proline-rich sequences. Recent data suggest that these activation motifs may use different mechanisms to interact with the general transcriptional machinery. In particular, the proline-rich CTF/NF1 protein appears to require a different set of coactivator molecules to mediate its interaction with TFIID and the other general factors than proteins containing acidic or glutaminerich activation domains (Pugh and Tjian 1990). It will be interesting to determine whether the AP-2 protein is distinct from these other transcription factors or whether it functions by the same process as CTF/NF1.

In conclusion, our results demonstrate that AP-2 has a modular design and is composed of distinct domains involved in transcriptional activation and DNA binding/ dimerization. The cDNA mutants generated in this study also provide the necessary reagents to determine which regions of AP-2 are the targets of positive and negative regulation by other factors. Furthermore, it is possible that some mutants will act as dominant negative suppressors of endogenous AP-2. Therefore, the AP2 protein may represent a useful tool in determining how the control of transcription factor activity affects gene expression and developmental regulation.

\section{Materials and methods}

Plasmid constructs for in vitro transcription

The AP-2 vectors used for in vitro transcription and cotransfection were derived from AP-2 linker. This plasmid was made by 
fusing an oligonucleotide $\left(5^{\prime}\right.$-CATGG TTTGG AAATT GACGG ATAAT ATCAA GT-3'; nucleotides 62-93) to an RsaIHindIII fragment of AP2-9 (nucleotide 94, through the EcoRI site at nucleotide 1636 , into the polylinker; Williams et al. 1988), and ligating this fusion into NcoI-HindIII-cleaved pKK233-2 (Pharmacia). This creates an NcoI site at the translational start of AP- 2 and causes a conservative change of the second amino acid from leucine to valine. An oligonucleotide (5'-ATCAG GCCTG ATTGA CTGAC TCGAG GGATC CA-3' was then inserted into the $3^{\prime}$ polylinker, between the EcoRV and HindIII sites. This reforms the EcoRV and HindIII sites and introduces stop codons in all three frames. A StuI site is also present $5^{\prime}$ to the stop codons, and an $\mathrm{XhoI}$ and BamHI site occurs to the $3^{\prime}$ side.

To generate 3 ' deletion mutants, fragments of AP-2 linker, from the $\mathrm{NcoI}$ site at nucleotide 62 to either the FnuDII site at nucleotide 1230 ( $\triangle \mathrm{C} 390)$, or a T4 DNA polymerase-repaired NcoI site at nucleotide 1289 ( $\triangle \mathrm{C} 409)$, were ligated into NcoIEcoRV-restricted AP-2 linker. $\triangle \mathrm{C} 413$ was made by ligating an AP-2 fragment from the $N c o$ site at nucleotide 62 to the $R s a I$ site at nucleotide 1299 into NcoI-StuI-restricted AP-2 linker. For $5^{\prime}$ deletion mutants, $\mathrm{NcoI}$ linkers were added to the $5^{\prime}$ ends of AP-2 restriction fragments, which terminated at their $3^{\prime}$ ends at the XhoI site of AP-2 linker. These fragments were then ligated into Ncol-Xhol-restricted AP-2 linker. The appropriate AP-2 open reading frame was maintained by using either an 8-mer, 10-mer, or 12-mer NcoI linker (Pharmacia). The $5^{\prime}$ ends of the relevant restriction fragments are $P$ vuII at nucleotide 153

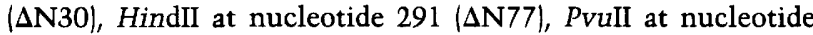
$414(\Delta \mathrm{N} 117), S m a I$ at nucleotide $557(\Delta \mathrm{N} 165), R s a \mathrm{I}$ at nucleotide $742(\Delta N 227), T 4$ DNA polymerase-repaired BglII at nucleotide $853(\Delta \mathrm{N} 263)$, T4 DNA polymerase-repaired PstI at nucleotide $896(\Delta \mathrm{N} 278)$, and $R s a \mathrm{I}$ at nucleotide $979(\Delta \mathrm{N} 306)$.

The AP-2-coding sequences, from the $N c o I$ site at nucleotide 62 to the XhoI site in the $3^{\prime}$ polylinker, were ligated into NcoISalI-restricted p $\beta$ Sal (Norman et al. 1988), generating p $\beta$ Sal AP2 wild type. The various deletions were constructed in a similar manner. The plasmid p $\beta$ Sal $\triangle \mathrm{N} 203$ was made from p $\beta$ Sal AP-2 wild type, using a $5^{\prime}$ oligonucleotide $5^{\prime}$-GG CAG CCC ATG GTG GTG AAC CCC AAC G-3' (which has sequence identity to nucleotides 672-686) for polymerase chain reaction (PCR) in conjunction with a $3^{\prime}$ oligonucleotide $5^{\prime}$-GGA TCG AAT TCC TCA CTT TCT GTG CTT CTC CTC TTT GTC-5' (which is complementary to nucleotides 1378-1350|. The PCR product was restricted with $\mathrm{NcOI}$ and ligated into $\mathrm{NcoI}$-digested $\mathrm{p} \beta \mathrm{Sal}$ AP-2 wild type, and a plasmid containing the correct orientation was identified. All AP-2 nucleotide numbers are given with reference to AP2-9 (Williams et al. 1988).

\section{In vitro transcription/translation and EMSAs}

The AP-2 p $\beta$ Sal derivative plasmids were linearized 3 ' to the coding region with $\mathrm{Xbal}$ and transcribed in vitro by using $\mathrm{T} 7$ RNA polymerase (Stratagene). The RNA was translated in nuclease-treated rabbit reticulocyte lysate (Promega) in the presence of $\left[{ }^{35} \mathrm{~S}\right]$ methionine, followed by RNase A treatment as recommended by the manufacturer. Different AP-2 polypeptides were only "mixed" following this RNase A treatment to ensure that cotranslation could not occur. EMSA was performed essentially as described (Ausubel et al. 1989). Briefly, $2.5 \mu 1$ of reticulocyte lysate was incubated in a buffer containing $10 \mathrm{~mm}$ Tris$\mathrm{Cl}(\mathrm{pH} 7.9), 4.5 \%$ Ficoll $400,60 \mathrm{~mm} \mathrm{KCl}, 4 \mathrm{~mm} \mathrm{MgCl}_{2}, 0.1 \mathrm{~mm}$ EDTA, $50 \mu \mathrm{g} / \mathrm{ml}$ of BSA, $0.2 \% \mathrm{NP}-40$, and $40 \mathrm{ng} / \mu \mathrm{l}$ of poly[d(IC) for $10 \mathrm{~min}$ on ice before the addition of ${ }^{32} \mathrm{P}$-end-labeled double-stranded AP-2 oligonucleotide $(10,000 \mathrm{cpm})$. Binding reactions were allowed to proceed for an additional $15 \mathrm{~min}$ on ice and were fractionated on pre-electrophoresed $15 \mathrm{~cm} 4 \%(40: 1)$ polyacrylamide $/ 0.25 \times \mathrm{TAE}$ gels containing $0.5 \% \mathrm{NP}-40$, at $4^{\circ} \mathrm{C}$. For analysis of heterodimer formation, $36-\mathrm{cm}$ gels were used. Gels were dried and exposed through two pieces of blank X-ray film to attenuate the ${ }^{35} \mathrm{~S}$ label and record only the ${ }^{32} \mathrm{P}$ signal. The AP-2 oligonucleotide was derived from hMtIIa (Williams et al. 1988). Autoradiography and Western blotting analysis of SDS-PAGE indicated that equivalent amounts of all proteins were made (data not shown).

\section{DNA methylation and missing contact interference analyses}

Experiments were performed essentially as described (Ausubel et al. 1989). Briefly, $20 \mu$ l of reticulocyte lysate containing AP-2 protein derived from $\mathrm{p} \beta \mathrm{Sal}$ AP- 2 wild type was incubated with $2 \times 10^{5} \mathrm{cpm}$ of modified probe in a scaled-up EMSA DNA-binding reaction. Following electrophoresis, the DNA was transferred to NA45 paper (Schleicher and Schuell) in EMSA gel running buffer at $4^{\circ} \mathrm{C}$ for $60 \mathrm{~min}$. The parts of the membrane corresponding to the bound and free probe were removed and analyzed as described by Singh et al. (1988). Autoradiograms of the sequencing ladders were quantitated using a Hoefer GS300 densitometer. The AP-2 oligonucleotides were derived from SV40 (Mitchell et al. 1987) and hMtIla (Williams et al. 1988). Single-stranded oligonucleotides were ${ }^{32} \mathrm{P}$-end-labeled with polynucleotide kinase on either the top or bottom strand, annealed with the unlabeled complementary strand, and purified on an $8 \%$ acrylamide gel. The probes were methylated, depurinated, or depyrimidinated according to the procedure of Maxam and Gilbert (1980).

\section{Cross-linking}

AP-2 proteins, made by in vitro translation in the presence of $\left[{ }^{35} \mathrm{~S}\right]$ methionine, were purified by DNA affinity chromatography using an AP-2 oligonucleotide derived from hMtIIa (Williams et al. 1988). Proteins were cross-linked with $0.001 \%$ glutaraldehyde for $60 \mathrm{~min}$ at room temperature and analyzed as described by Turner and Tjian (1989).

\section{Coimmunoprecipitation}

The AP- 2 proteins, made by in vitro translation in the presence of $\left[{ }^{35}\right.$ S $]$ methionine, were immunoprecipitated using an affinitypurified antisera specific for the amino terminus of AP-2 (Lüscher et al. 1989). Immunoprecipitation was performed in RIPA buffer $(150 \mathrm{~mm} \mathrm{NaCl}, 10 \mathrm{~mm}$ Tris- $\mathrm{Cl}$ at $\mathrm{pH} 7.4,1 \%$ Triton $\mathrm{X}-100,1 \%$ sodium deoxycholate, 1 mM EDTA, $1 \mathrm{mM}$ PMSF, and $2 \mu \mathrm{g} / \mathrm{ml}$ aprotinin) using protein A-Sepharose (Pharmacia) essentially as described (Ausubel et al. 1989). Proteins were separated by SDS-PAGE and visualized by fluorography following treatment of the gel with Amplify (Amersham).

\section{Plasmid constructs for transfection}

The reporter constructs, BCAT containing the Elb TATA box, and G5BCAT, which also contains five GAL4-binding sites, have been described previously. (Lillie and Green 1989). A2BCAT was made by inserting three copies of the sequence 5'-CTGAC CGCCC GCGGC CCGT-3', corresponding to nucleotides -185 to -167 of the hMtIla distal BLE, into the SalI site of BCAT. All three AP-2 sites are oriented toward the TATA box. Similar results are obtained if the three AP- 2 sites are inserted in the opposite orientation (data not shown).

The mammalian expression vector SPRSV was derived from RSV-2 (generous gift of C. Gorman), by inserting an 8-mer NcoI 
linker (GCCATGGC) into the SmaI site of the polylinker. The NdeI-PvuIl fragment, spanning the RSV LTR, the polylinker, and the SV40 poly(A) signal, was then inserted into NdeIEcoRV-restricted pSP72 (Promega), generating SPRSV. The wild-type AP-2 vector, SPRSV-AP2, was made by ligating a fragment of AP-2 linker, from the NcoI site at nucleotide 62 to the $X$ hoI site in the $3^{\prime}$ polylinker, into NcoI-XhoI-restricted SPRSV. Similarly, SPRSV $\Delta N 77, \Delta C 413$, and $\Delta C 390$ were made from their pKK derivatives. SPRSV $\triangle N 51$ was made by ligating an oligonucleotide 5'-CATGG CCGAC TTCCA GCCCC CATAC TTCCC CCCAC CCTAC CAGCC TATCT ACCCC CAGTC GCAAG ATCCT TACTC CCACG TC-3' to SPRSV-AP2 lacking an NcoI-HindII fragment (nucleotides 62-290). Similarly, SPRSV $\triangle \mathrm{N} 65$ was made using an oligonucleotide 5 '-CATGG CCATC TACCC CCAGT CGCAA GATCC TTACT CCCAC GTC-3'. For the RSV internal deletion mutants, INT 31/77 was made by removing a PvuII-HindII fragment (nucleotides 153290 ); INT $77 / 117$, by removing a HindII-PvuII fragment (nucleotides $291-413$ ); INT $97 / 117$, by removing a HaeIII-PvuII fragment (nucleotides 351-413); INT 97/165, by removal of a HaeIII-XmaI fragment, and T4 DNA polymerase repairing the remaining XmaI overhang (nucleotides 351-554); and INT 123/ 171 , by removing a Sau3a fragment (nucleotides 430-572).

The GAL4/AP-2 plasmids were based on pSG424 (Sadowski and Ptashne 1989), which encodes amino acids 1-147 of GAL4. The fusions were made by ligating fragments of AP-2 into the SmaI site 3' to the GAL4-coding sequences; GAL4 $+6 / 165$ is a HpaI-SmaI fragment (nucleotides 77-556) from pAP2L (Williams et al. 1988); GAL4 $+6 / 117$ is a HpaI-PvulI fragment from pAP2L (nucleotides $77-413$ ); GAL4 $+6 / 77$ is a HpaIHindII fragment from pAP2L (nucleotides 77-290); GAL4 $+77 / 165$ is a T4 DNA polymerase-repaired NcoI-SmaI fragment from SPRSV $\triangle \mathrm{N} 77$ (nucleotides 291-556); GAL4 $+117 / 165$ is a T4 DNA polymerase-repaired NcoI-SmaI fragment from SPRSV $\triangle \mathrm{N} 117$ (nucleotides 414-556); and GAL4 $+6 / 437$ is a HpaI-EcoRV fragment of PAP2L, from nucleotide 77 to the EcoRV site in the $3^{\prime}$ polylinker.

\section{Cotransfection assays}

Cotransfection of HepG2 cells and CAT assays was essentially as described (Baichwal and Tjian 1990). Transfections contained $5 \mu \mathrm{g}$ of reporter construct with either $1 \mu \mathrm{g}$ of SPRSV plasmids or $5 \mu \mathrm{g}$ of GAL4 plasmids. The amount of DNA per transfection was brought to a total of $15 \mu \mathrm{g}$ with puc118 carrier DNA. Transfections were performed at least twice in duplicate.

\section{Acknowledgments}

We are indebted to all the members of the Tjian laboratory for their helpful criticism and suggestions throughout the course of this work. We are grateful to Naoko Tanese, Vijay Baichwal, and Laura Attardi for critical reading of the manuscript. We thank Drs. C. Gorman, R. Treisman, and C. Norman for the gift of plasmids, Laura Attardi for assistance with the construction of deletion mutants, and Adam Park for performing the tissue culture. This work was supported in part by a grant from the $\mathrm{Na}$ tional Institutes of Health (R.T.) and a Howard Hughes Medical Institute postdoctoral fellowship (T.W.).

The publication costs of this article were defrayed in part by payment of page charges. This article must therefore be hereby marked "advertisement" in accordance with 18 USC section 1734 solely to indicate this fact.

\section{References}

Appelbaum, E.R., D.V. Thompson, K. Idler, and N. Chartrain.
1988. Rhizobium japonicum USDA 191 has two nodD genes that differ in primary sequence and function. 1. Bacteriol. 170: $12-20$.

Ausubel, F.M., R. Brent, R.E. Kingston, D.D. Moore, J.G. Seidman, J.A. Smith, and K. Struhl. 1989. Current protocols in molecular biology. Greene Publishing Associates/Wiley-Interscience.

Baeuerle, P.A. and D. Baltimore. 1988. IкB: A specific inhibitor of the NF-kB transcription factor. Science 242: 540-546.

Baichwal, V.R. and R. Tjian. 1990. Control of c-jun activity by interaction of a cell-specific inhibitor with regulatory domain $\delta$ : Differences between v- and c-jun. Cell 63: 815-825.

Benezra, R., R.L. Davis, D. Lockshon, D.L. Turner, and H. Weintraub. 1990. The protein Id: A negative regulator of helixloop-helix DNA binding proteins. Cell 61: 49-59.

Courtois, S.J., A. Lafontaine, F.P. Lemaigre, S.M. Durviaux, and G.G. Rousseau. 1990. Nuclear factor-1 and activating protein-2 bind in a mutually exclusive way to overlapping promoter sequences and trans-activate the human growth hormone gene. Nucleic Acids Res. 18: 57-64.

Cress, W.D. and S.J. Triezenberg. 1991. Critical structural elements of the VP16 transcriptional activation domain. Science 251: 87-90.

Evans, R.M. and S.M. Hollenberg. 1988. Zinc fingers: Gilt by association. Cell 52: 1-3.

Garrell, J. and J. Modolell. 1990. The Drosophila extramacrochaetae locus, an antagonist of proneural genes that, like these genes, encodes a helix-loop-helix protein. Cell 61: 3948.

Gerster, T., C.-G. Balmaceda, and R.G. Roeder. 1990. The cell type-specific octamer transcription factor OTF-2 has two domains required for the activation of transcription. EMBO J. 9: 1635-1643.

Herr, W., R.A. Sturm, R.G. Clerc, L.M. Corcoran, D. Baltimore, P.A. Sharp, H.A. Ingraham, M.G. Rosenfeld, M. Finney, G. Ruvkun, and H.R. Horvitz. 1988. The POU domain: A large conserved region in the mammalian pit-1, oct-1, oct-2, and Caenorhabditis elegans unc-86 gene products. Genes 4 Dev. 2: 1513-1516.

Hochschild, A., N. Irwin, and M. Ptashne. 1983. Repressor structure and the mechanism of positive control. Cell 32: 319-325

Hoey, T. and L. Levine. 1988. Divergent homeo box proteins recognize similar DNA sequences in Drosophila. Nature 332: 858-861.

Hollenberg, S.M., V. Giguere, P. Segui, and R.M. Evans. 1987. Colocalization of DNA-binding and transcriptional activation functions in the human glucocorticoid receptor. Cell 49: 39-46.

Hyman, S.E., M. Comb, I. Pearlberg, and H.M. Goodman. 1989. An AP-2 element acts synergistically with the cAMP and phorbol ester inducible enhancer of the human proenkephalin gene. Mol. Cell. Biol. 9: 321-324.

Imagawa, M., R. Chiu, and M. Karin. 1987. Transcription factor AP-2 mediates induction by two different signal-transduction pathways: Protein kinase C and cAMP. Cell 51: 251260.

Israël, A., O. Le Bail, D. Hatat, P. Piette, M. Kieran, F. Logeat, D. Wallach, M. Fellous, and P. Kourilsky. 1989. TNF stimulates expression of mouse MHC class I genes by inducing an NFkB-like enhancer binding activity which displaces constitutive factors. $E M B O /$. 8: 3793-3800.

Jantzen, H.M., A. Admon, S.P. Bell, and R. Tjian. 1990. Nucleolar transcription factor hUBF contains a DNA-binding motif with homology to HMG proteins. Nature 344: 830-836.

Jones, N. 1990. Transcriptional regulation by dimerization: 
Two sides of an incestuous relationship. Cell 61:9-11.

Kanno, M., C. Fromental, A. Staub, F. Ruffenach, I. Davidson, and P. Chambon. 1989. The SV40 TC-II $(\kappa B)$ and the related $\mathrm{H}-2 \mathrm{~K}^{\mathrm{B}}$ enhansons exhibit different cell type specific and inducible proto-enhancer activities, but the SV40 core sequence and the AP-2 binding site have no enhanson properties. EMBO I. 8: 4205-4214.

Karin, M., A. Haslinger, A. Heguy, T. Dietlin, and T. Cooke. 1987. Metal-response elements act as positive modulators of human metallothionein-IIa enhancer activity. Mol. Cell. Biol. 7: 606-613.

Landschulz, W.H., P.F. Johnson, and S.J. McKnight. 1989. The DNA binding domain of the rat liver nuclear protein C/EBP is bipartite. Science 243: 1681-1688.

Lillie, J.W. and M.R. Green. 1989. Transcription activation by the adenovirus E1a protein. Nature 338: 39-44.

Lüscher, B., P.J. Mitchell, T. Williams, and R. Tjian. 1989. Regulation of transcription factor AP-2 by the morphogen retinoic acid and by second messengers. Genes $\Leftrightarrow$ Dev. 3: 15071517.

Macchi, M., J.-M. Bornert, I. Davidson, K. Kanno, R. Rosales, M. Vigneron, J.-H. Xiao, C. Fromental, and P. Chambon. 1989. The SV40 TC-II ( $\mathrm{kB})$ enhanson binds ubiquitous and cell type specifically inducible nuclear proteins from lymphoid and non-lymphoid cell lines. EMBO I. 8: 4215-4227.

Maxam, A.M. and M. Gilbert. 1980. Sequencing end-labelled DNA with base-specific chemical cleavages. Methods Enzymol. 65: 499-560.

Mercurio, F. and M. Karin. 1989. Transcription factor AP-3 and AP-2 interact with the SV40 enhancer in a mutually exclusive manner. $E M B O$ I. 8: 1455-1460.

Mermod, N., E.A. O'Neill, T.J. Kelly, and R. Tjian. 1989. The proline-rich transcriptional activator of CTF/NF-I is distinct from the replication and DNA binding domain. Cell 58: 741-753.

Miesfeld, R., P.J. Godowski, B.A. Maler, and K.R. Yamamoto. 1987. Glucocorticoid receptor mutants that define a small region sufficient for enhancer activation. Science 236: 423 427.

Mitchell, P.J. and R. Tiian. 1989. Transcriptional regulation in mammalian cells by sequence-specific DNA binding proteins. Science 245: 371-8.

Mitchell, P.J., C. Wang, and R. Tjian. 1987. Positive and negative regulation of transcription in vitro: Enhancer-binding protein AP-2 is inhibited by SV40 T antigen. Cell 50: $847-$ 861.

Mitchell, P.J., P.M. Timmons, J.M. Hébert, P.W.J. Rigby, and R. Tjian. 1991. Transcription factor AP-2 is expressed in neural crest cell lineages during mouse embryogenesis. Genes 4$)$ Dev. 5: 105-119.

Murre, C., P.S. McCaw, and D. Baltimore. 1989. A new DNA binding and dimerization motif in immunoglobin enhancer binding, daughterless, MyoD and myc proteins. Cell 56: 777-783.

Norman, C., M. Runswick, R. Pollock, and R. Treisman. 1988. Isolation and properties of cDNA clones encoding SRF, a transcription factor that binds to the c-fos serum response element. Cell 55: 989-1003.

Nyborg, J.K. and W.S. Dynan. 1990. Interaction of cellular proteins with the human T-cell leukemia virus type I control region. I. Biol. Chem. 265: 8230-8236.

Ptashne, M. 1988. How eukaryotic transcriptional activators work. Nature 335: 683-689.

Pugh, B.F. and R. Tjian. 1990. Mechanism of transcriptional activation by Spl: Evidence for coactivators. Cell 61: 11871197.
Roesler, W.J., G.R. Vandenbark, and R.W. Hanson. 1988. Cyclic AMP and the induction of eukaryotic gene transcription. $J$. Biol. Chem. 263: 9063-9066.

Sadowski, I. and M. Ptashne. 1989. A vector for expressing GAL4 (1-147) fusions in mammalian cells. Nucleic Acids Res. 17: 7539 .

Seto, E., P.J. Mitchell, and T.S.B. Yen. 1990. Transcription by the hepatitis B virus X protein depends on AP-2 and other transcription factors. Nature 344: 72-74.

Singh, H., J. LeBowitz, A. Baldwin, and P.A. Sharp. 1988. Molecular cloning of an enhancer binding protein: Isolation by screening of an expression library with a recognition site DNA. Cell 52: 415-423.

Turner, R. and R. Tjian. 1989. Leucine repeats and an adjacent DNA binding domain mediate the formation of functional cFos-cJun heterodimers. Science 243: 1689-1694.

Williams, T. and R. Tjian. 1991. The AP-2 helix-span-helix domain defines a novel dimerization module that can be utilized by heterologous DNA binding proteins. Science (in press).

Williams, T., A. Admon, B. Lüscher, and R. Tjian. 1988. Cloning and expression of AP-2, a cell-type-specific transcription factor that activates inducible enhancer elements. Genes 4$)$ Dev. 2: 1557-1569. 


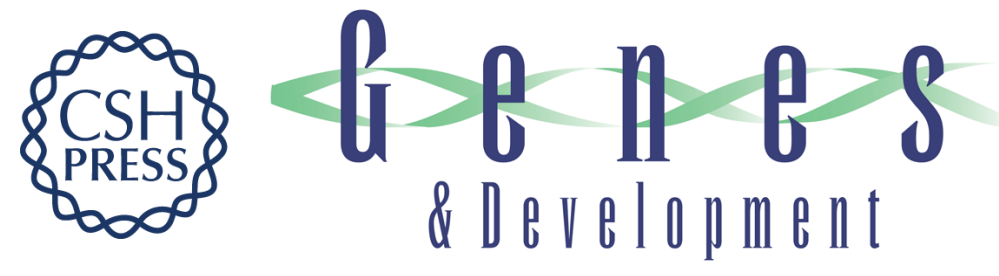

\section{Analysis of the DNA-binding and activation properties of the human transcription factor AP-2.}

T Williams and R Tjian

Genes Dev. 1991, 5:

Access the most recent version at doi:10.1101/gad.5.4.670

References This article cites 41 articles, 14 of which can be accessed free at:

http://genesdev.cshlp.org/content/5/4/670.full.html\#ref-list-1

License

Email Alerting

Service

Receive free email alerts when new articles cite this article - sign up in the box at the top right corner of the article or click here.

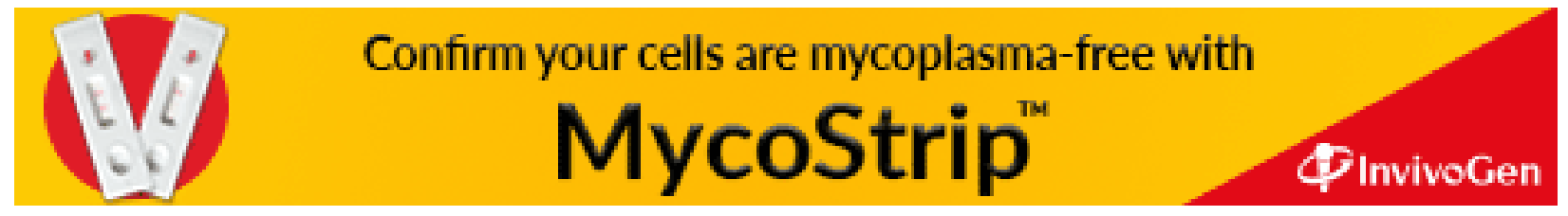

